\title{
The separation of arsenic metabolites in urine by high performance liquid chromatography- inductively coupled plasma-mass spectrometry
}

\author{
Jin-Yong Chung ${ }^{1}$, Hyoun-Ju Lim ${ }^{1}$, Young-Jin Kim² ${ }^{2}$ Ki-Hoon Song ${ }^{3}$, Byoung-Gwon Kim ${ }^{1,4}$, \\ Young-Seoub Hong ${ }^{1,4}$ \\ ${ }^{1}$ Heavy Metal Exposure Environmental Health Center, Dong-A University, Busan; ${ }^{2}$ Agilent Technologies Korea Ltd., Seoul; \\ ${ }^{3}$ Department of Dermatology, Dong-A University Hospital, Busan; ${ }^{4}$ Department of Preventive Medicine, Dong-A University \\ College of Medicine, Busan, Korea
}

\begin{abstract}
Objectives The purpose of this study was to determine a separation method for each arsenic metabolite in urine by using a high performance liquid chromatography (HPLC)inductively coupled plasma-mass spectrometer (ICP-MS).

Methods Separation of the arsenic metabolites was conducted in urine by using a polymeric anion-exchange (Hamilton PRP X-100, $4.6 \mathrm{~mm} \times 150 \mathrm{~mm}, 5 \mu \mathrm{m}$ ) column on Agilent Technologies 1260 Infinity LC system coupled to Agilent Technologies 7700 series ICP/MS equipment using argon as the plasma gas.

Results All five important arsenic metabolites in urine were separated within 16 minutes in the order of arsenobetaine, arsenite, dimethylarsinate, monomethylarsonate and arsenate with detection limits ranging from 0.15 to $0.27 \mu \mathrm{g} / \mathrm{L}$ ( $40 \mu \mathrm{L}$ injection). We used $\mathrm{G}$ EQUAS No. 52, the German external quality assessment scheme and standard reference material 2669, National Institute of Standard and Technology, to validate our analyses. Conclusions The method for separation of arsenic metabolites in urine was established by using HPLC-ICP-MS. This method contributes to the evaluation of arsenic exposure, health effect assessment and other bio-monitoring studies for arsenic exposure in South Korea.
\end{abstract}

Keywords : Arsenic, Arsenic metabolites, HPLC-ICP-MS, Urine

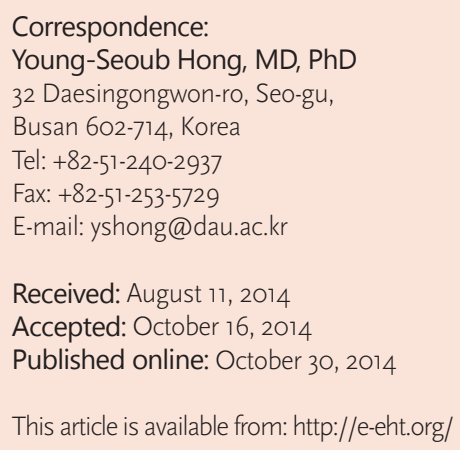

\section{Introduction}

Arsenic, a metalloid and naturally occurring element, is one of the most abundant elements in the earth's crust and is found throughout our environment. Arsenic is primarily used as an insecticide, as an herbicide due to its germicidal power, and as a preservative for wood to make it resistant to rot and decay resistant. Arsenic compounds are easily dissolved in water, therefore chronic arsenic effect from ingestion of arsenic-contaminated food and water or inhalation from the air has been investigated from many research groups in several countries. Arsenic expo- sure has been associated with detrimental health impacts such as hyperpigmentation, keratosis, skin and other types of cancer and vascular disease $[1,2]$. Because of the human health risk of arsenic, the International Agency for Research on Cancer (IARC) has classified arsenic as a group I human carcinogen [3]. It is believed that arsenic is a unique human carcinogen according to investigation into its carcinogenic effects over the last several decades. In regard to the carcinogenic effects of arsenic, recent studies have shown that cigarette smoking and ingestion of arsenic-containing drinking water at the same time significantly increased the synergistic effects of lung cancer [4]. In ad- 
dition, other groups have suggested that a significant correlation between arsenic exposure and skin cancer has been observed [5]. There is also obvious evidence about the non-carcinogenic related effects of arsenic, including the chronic effect of arsenic exposure being strongly associated with spontaneous abortion and stillbirth [6], cardiovascular disease [7], disruption of hormonal systems [8], and type two diabetes mellitus [9].

Once arsenic compounds have been absorbed through various routes, such as the respiratory system or via food consumption, they are generally processed via a metabolic pathway in the liver [10], being converted into many different types of inorganic and organic species including arsenite $\left(\mathrm{As}^{3+}\right)$, arsenate $\left(\mathrm{As}^{5+}\right)$, dimethylarsinate (DMA), and monomethylarsonate (MMA). Arsenic metabolites in the body are eventually excreted into the urine, which is the major excretion pathway for the elimination of arsenic species from the body (Figure 1). Each arsenic form has a different physiological and bioactive property, hence it is necessary to identify and quantify each various arsenic chemical form for evaluation of human health risks related to arsenic exposure. In addition, previous studies have demonstrated that the total arsenic concentration, known as the sum of DMA, MMA and inorganic arsenic, is not sufficient for health risk assessment $[11,12]$. There have been several studies on the assessment of arsenic exposure in South Korea [13,14], but separation of arsenic metabolites in the general population in South Korea has not yet been reported. The toxicity of arsenic is strongly dependent on its chemical species present in the body. It is generally known that the inorganic forms of arsenic, such as $\mathrm{As}^{3+}$ and $\mathrm{As}^{5+}$, are more toxic than the organic arsenic, such as DMA and MMA, and among the inorganic arsenic species, $\mathrm{As}^{3+}$ is more toxic than $\mathrm{As}^{5+}[15-17]$. In order to estimate human urinary arsenic metabolites, seafood ingestion should be prohibited at least 3 to 4 days prior to urine sample collection to avoid over estimation of urinary arsenic species. It is well known that some seafoods contain arsenic, including arsenobetaine in crustaceans and arsenosugars in seaweeds [18]. Thus, the aim of this study was to design an analytical procedure for separation of urinary arsenic metabolites by using high performance liquid chromatography (HPLC)-inductively coupled plasma-mass spectrometer (ICPMS). Using this method, it will contribute to the evaluation of arsenic exposure, human health effect assessment and other biomonitoring studies of arsenic exposure in South Korea.

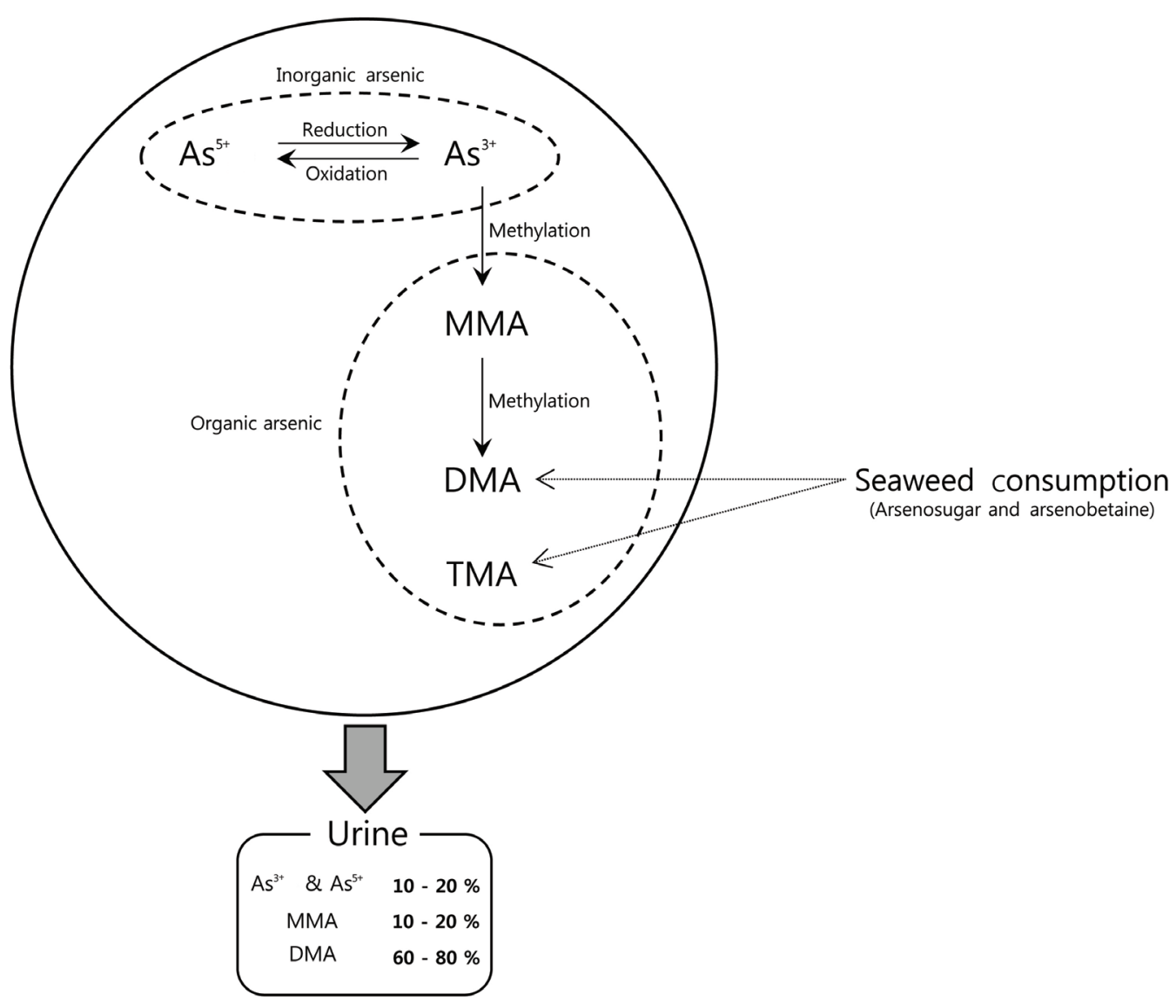

Figure 1. Arsenic metabolism in the human body. $\mathrm{As}^{3+}$, arsenate; $\mathrm{As}^{5+}$, arsenate; MMA, monomethylarsonate; DMA, dimethylarsinate; TMA, trimethylarsine. 


\section{Materials and Methods}

\section{Apparatus}

For the separation of individual arsenic species, we used an Agilent Technologies 7700 series ICP-MS instrument (Agilent Technologies, Santa Clara, CA, USA), equipped with a lowflow sample introduction system and patented high matrix introduction kit. The HPLC system (Agilent Technologies) consisted of an Agilent 1260 Infinity Quaternary Pump VL, standard auto-sampler, and thermostat column compartment, equipped with Peltier cooling and heating apparatus for providing temperature stability and application flexibility. All samples were filtered with a $0.22 \mu \mathrm{m}$ membrane before being placed into chromatographic vials (Agilent Technologies), then placed on the auto-sampler tray. A PRP X-100 anion-exchange HPLC column ( $5 \mu \mathrm{m}, 4.6 \mathrm{~mm} \times 250 \mathrm{~mm}$, Hamilton, Bonaduz, Switzerland) was used for arsenic species separation. The column was packed with a 55\% cross-linked polystyrene divinylbenzene copolymer functionalized with quaternary ammonium anion-exchanger groups. The outlet of the column was directly connected to the sample introduction system of ICP-MS instrument. Reading data were collected by using Mass Hunter Workstation version B.01.01 (Agilent Technologies). The operating conditions for HPLC and ICP-MS are shown in Table 1.

\section{Reagents}

Deionized water was used for preparation and dilution of reagents, urine samples, and calibration solutions. Calibration solution supplied by Agilent Technologies, South Korea was prepared by dilution with deionized water from $1,000 \mathrm{mg} / \mathrm{L}$ stock. Standard reference material (SRM) and German external quality assessment scheme (G-EQUAS) No. 52 were used for internal control and accuracy of HPLC-ICP-MS. SRM 2669 was obtained from the National Institute of Standards and Technology (NIST) and G-EQUAS No. 52 was obtained from ErlangenNuremberg University, Germany. Prepared SRM was stored at $-80^{\circ} \mathrm{C}$ until use. The reagents used in HPLC mobile phase, including ammonium carbonate, Tris, and ammonium sulfate (Sigma-Aldrich, St. Louis, MO, USA), were prepared in deionized water and filtered through a $0.45 \mu \mathrm{m}$ membrane before use. These mobile phase reagents were prepared fresh daily. All reagents were analytical grade or better.

\section{Linearity and Calibration Curves}

Calibration was performed on five points over a concentration
Table 1. HPLC and ICP-MS operating conditions for the separation of urinary arsenic metabolites

\begin{tabular}{|c|c|}
\hline Parameter & Setting \\
\hline \multicolumn{2}{|l|}{ HPLC parameters and settings } \\
\hline Instrument & $\begin{array}{l}\text { Agilent Technologies } 1260 \text { Infinity } \\
1260 \text { Quat Pump VL }\end{array}$ \\
\hline Analytical column & Hamilton PRP-X100, 5 um \\
\hline Column dimensions & $4.6 \times 250 \mathrm{~mm}$ \\
\hline Pump flow rate & $1.0 \mathrm{~mL} / \mathrm{min}$ \\
\hline Injection volume & $40 \mu \mathrm{L}$ \\
\hline Mobile phase A & $\begin{array}{l}10 \mathrm{mM} \text { ammonium carbonate } \\
10 \mathrm{mM} \text { Tris } \\
\text { pH } 9.2\end{array}$ \\
\hline Mobile phase B & $\begin{array}{l}10 \mathrm{mM} \text { ammonium carbonate } \\
10 \mathrm{mM} \text { Tris } \\
15 \mathrm{mM} \text { ammonium sulfate } \\
\text { pH } 8.8\end{array}$ \\
\hline \multirow[t]{4}{*}{ Gradient elution program } & 00-05 min: "A" 100\% \\
\hline & 05-11 min: "B" 100\% \\
\hline & 11-13 min: "B" 100\% \\
\hline & 13-16 min: "A" 100\% \\
\hline \multicolumn{2}{|l|}{ ICP-MS parameter and setting } \\
\hline Instrument & Agilent Technologies 7700 series \\
\hline RF power & $1,550 \mathrm{~W}$ \\
\hline RF matching & $1.80 \mathrm{~V}$ \\
\hline Carrier gas flow rate & $1.05 \mathrm{~L} / \mathrm{min}$ \\
\hline Sampler and skimmer cones & Nickel \\
\hline Spray chamber temp & $2^{\circ} \mathrm{C}$ \\
\hline He flow rate & $4.3 \mathrm{~mL} / \mathrm{min}$ \\
\hline Nebulizer & Concentric nebulizer \\
\hline
\end{tabular}

HPLC, high performance liquid chromatography; ICP-MS, inductively coupled plasma-mass spectrometer.

range of 1 to $20 \mu \mathrm{g} / \mathrm{L}$. More than three calibration standards for each calibration point were prepared. Measurements for each calibration were averaged, then calibration curves were obtained, which resulted in good correlation coefficients of at least 0.9998 .

\section{Precision and Accuracy}

In order to validate the analytical procedure, within-day and between-day precision measurements were conducted by calculating the average, standard deviation (SD), and coefficient of variation (CV) using NIST SRM 2669 (Gaithersburg, MD, USA), and G-EQUAS No. 52. Accuracy was calculated by the recovery rate in all repeated analyses, using SRM 2669, and GEQUAS No. 52.

\section{Statistical Analysis}

For statistical analysis, SAS version 9.3 (SAS Institute Inc., Cary, NC, USA) was used. Data are expressed as the mean \pm SD 
of separate experiments.

\section{Results}

\section{Linearity and Calibration Curves}

To validate analysis accuracy, calibration was performed several times and the average signal intensity value for each calibration was used to make the calibration curves. The calibration curves of each five point arsenic species showed satisfactory linearity for $\mathrm{As}^{3+}, \mathrm{As}^{5+}, \mathrm{DMA}$, and MMA (Figure S1). Retention times of arsenic metabolites, such as $\mathrm{As}^{3+}$, DMA, MMA, and $\mathrm{As}^{5+}$, are listed in Figure S2. The four major arsenic metabolites were separated within 16 minutes.

\section{Repeatability, Accuracy, and Recovery rates}

To validate repeatability and accuracy, we used two certified materials, NIST SRM 2669 and the G-EQUAS No. 52 urine sample. These certified materials provided the reference and tolerance values, enabling HPLC-ICP-MS to be used for the quantification of arsenic speciation. A reference values of four arsenic species in SRM 2669 were provided by NIST as follows 5.03 for $\mathrm{As}^{3+}, 25.3$ for DMA, 7.18 for MMA, and 6.16 for $\mathrm{As}^{5+}$, respectively. Reference values for G-EQUAS No. 52 were also provided by the manufacturer. Five replicate analyses with each certified material are summarized in Table 2, which show good results compared to the reference values. We further confirmed recovery rate for the separation of arsenic metabolites using two certified materials by HPLC-ICP-MS. Over 5 replicates samples of the certified materials were used for the recovery test. In the case of the G-EQUAS No. 52 samples, relative standard deviation values ranged from $8.38 \%$ for $\mathrm{As}^{3+}, 4.12 \%$ for $\mathrm{As}^{5+}, 3.44 \%$ for DMA, and 9.85\% for MMA, respectively. Although recovery values gathered for all arsenic species were more diverse, values of over $90 \%$ were obtained through our arsenic species separation method. Even though other materials, including SRM 2669 , provided small certified values, recovery values were almost the same as the G-EQUAS No. 52 sample, except for $\mathrm{As}^{3+}$ (Table 2). Within-day and between-day precision with two certified materials were also evaluated. CVs of four arsenic species in NIST SRM 2669 and G-EQUAS No. 52 sample revealed lower than $10 \%$ precision, respectively (Table 3 ). Those results clearly demonstrated that separation of arsenic metabolites in urine sample by using HPLC-ICP-MS could be an applicable method for the general population.

\section{Limit of Detection}

Limit of detection (LOD) using HPLC-ICP-MS was also confirmed. To evaluate LOD, single standard solution $(1 \mu \mathrm{g} / \mathrm{L})$ was selected, then the concentration of the sample was determined over 10 times. The standard deviation for 10 samples was 0.05 for $\mathrm{As}^{3+}, 0.09$ for DMA, 0.09 for MMA, and 0.05 for $\mathrm{As}^{5+}$. The LOD of each arsenic species is summarized in Table 4.

\section{Speciation of Arsenic in Urine Samples}

To validate whether this method for separation of arsenic metabolites using HPLC-ICP-MS is appropriate for human urine samples, we further applied this method using five human urine samples. These samples were obtained from the Environmental Health Center, Dong-A University (IRB 13-063, Dong-A University Hospital). The concentrations of arsenic metabolites in these samples were obtained from five replicate HPLC-ICP-MS analyses, the results are shown in Table 5. Consistent with previous studies, results using human urine samples showed that DMA was the major arsenic metabolite in human urine samples. In addition, the sum of inorganic arsenic $\left(\mathrm{As}^{3+}\right.$ and $\left.\mathrm{As}^{5+}\right)$ concentrations in the samples was shown to be within the range re-

Table 2. Recovery values of the arsenic metabolite separation analysis, using standard reference material (SRM) 2669 and G-EQUAS No. 52 samples, by HPLC-ICP-MS $(\mu \mathrm{g} / \mathrm{L})$

\begin{tabular}{|c|c|c|c|c|c|}
\hline Certified material & Arsenic species & Certified value $\pm S D$ & Detection value mean $\pm S D$ & RSD (\%) & Recovery (\%) \\
\hline \multirow[t]{4}{*}{ NIST SRM 2669} & $\mathrm{As}^{3+}$ & $5.03 \pm 0.31$ & $3.42 \pm 0.31$ & 8.91 & 67.5 \\
\hline & DMA & $25.31 \pm 0.74$ & $25.37 \pm 0.76$ & 3.01 & 99.3 \\
\hline & MMA & $7.18 \pm 0.56$ & $6.83 \pm 0.35$ & 5.21 & 96.1 \\
\hline & $A s^{5+}$ & $6.16 \pm 0.95$ & $5.83 \pm 0.37$ & 6.39 & 94.6 \\
\hline \multirow[t]{4}{*}{ G-EQUAS No. 52} & $\mathrm{As}^{3+}$ & $3.05 \pm 0.91$ & $2.76 \pm 0.23$ & 8.38 & 92.0 \\
\hline & DMA & $16.82 \pm 3.35$ & $18.51 \pm 0.64$ & 3.44 & 110.0 \\
\hline & MMA & $3.01 \pm 1.21$ & $2.89 \pm 0.28$ & 9.85 & 96.0 \\
\hline & $A s^{5+}$ & $4.61 \pm 1.52$ & $5.66 \pm 0.23$ & 4.12 & 123.0 \\
\hline
\end{tabular}

SD, standard deviation; RSD, relative standard deviation; NIST, National Institute of Standard and Technology; As $^{3+}$, arsenite; DMA, dimethylarsinate; MMA, monomethylarsonate; $\mathrm{As}^{5+}$, arsenate. 
J-Y Chung, et al. I The separation of arsenic metabolites by HPLC-ICP-MS

Table 3. Concentration of arsenic metabolites in SRM 2669 and G-EQUAS No. 52 sample, obtained from 15 replicate determinations by HPLC-ICP-MS ( $\mu$ g/L)

\begin{tabular}{|c|c|c|c|c|c|}
\hline & & Arsenite & Dimethylarsinate & Monomethylarsonate & Arsenate \\
\hline \multicolumn{6}{|l|}{ NIST-2669, human urine } \\
\hline \multirow[t]{3}{*}{ Within-day precision $(n=3)$} & Mean & 3.13 & 25.14 & 6.90 & 5.83 \\
\hline & SD & 0.09 & 0.62 & 0.29 & 0.17 \\
\hline & CV (\%) & 2.94 & 2.45 & 4.15 & 2.96 \\
\hline \multirow[t]{3}{*}{ Between-day precision $(n=15)$} & Mean & 3.40 & 25.37 & 6.80 & 5.80 \\
\hline & SD & 0.30 & 0.76 & 0.35 & 0.37 \\
\hline & CV (\%) & 8.90 & 3.01 & 5.21 & 6.39 \\
\hline \multicolumn{6}{|l|}{ G-EQUAS No. 52, human urine } \\
\hline \multirow[t]{3}{*}{ Within-day precision (n=3) } & Mean & 2.90 & 17.64 & 2.67 & 5.59 \\
\hline & SD & 0.03 & 0.26 & 0.10 & 0.36 \\
\hline & CV (\%) & 1.15 & 1.50 & 3.65 & 6.38 \\
\hline \multirow[t]{3}{*}{ Between-day precision $(n=15)$} & Mean & 2.76 & 18.51 & 2.89 & 5.66 \\
\hline & SD & 0.23 & 0.64 & 0.28 & 0.23 \\
\hline & CV (\%) & 8.38 & 3.44 & 9.85 & 4.12 \\
\hline
\end{tabular}

SRM, standard reference material; NIST, National Institute of Standard and Technology; SD, standard deviation; CV, coefficient of variation.

Table 4. Limit of detection (LOD) of each arsenic metabolites $(\mu \mathrm{g} / \mathrm{L})$

\begin{tabular}{ccccc}
\hline & Arsenite & Dimethylarsinate & Monomethylarsonate & Arsenate \\
\hline LOD & 0.15 & 0.27 & 0.27 & 0.16
\end{tabular}

ported by the American Conference of Government Industrial Hygienists (ACGIH, $10 \mu \mathrm{g} / \mathrm{L}$ ). In case of organic arsenic, since eating seafood was not strictly prohibited for 3 days before collecting urine samples, DMA results might have been affected by seafood ingestion.

\section{Discussion}

This study was performed to evaluate arsenic speciation in urine using a HPLC-ICP-MS technique. Arsenic is of interest in the field of arsenic metabolites separation analysis due to different toxicities being associated with different chemical forms. Inorganic arsenic, such as $\mathrm{As}^{3+}$ and $\mathrm{As}^{5+}$, is considered the most toxic form among arsenic metabolites, therefore arsenic is classified as genotoxic and carcinogenic by the IARC [19,20]. Previous studies have shown that chronic arsenic exposure can cause various human diseases. Recently, diabetes mellitus has been linked with arsenic-contaminated drinking water [21,22]. After arsenic consumption into the body, arsenic is metabolized into various types of arsenic chemical forms, then usually excreted in the urine, so urinary measurement is a major factor in biomarker determination for arsenic exposure assessment in humans. In this study, we have developed a method for separation of arsenic metabolites from urine using certified materials with HPLCICP-MS. All four major arsenic metabolites were separated within 16 minutes with detection limits ranging from 0.15 to $0.27 \mu \mathrm{g} / \mathrm{L}$. It suggested that this method could be used for ana-
Table 5. Concentrations of arsenic metabolites in human urine samples $(\mu \mathrm{g} / \mathrm{L})$

\begin{tabular}{|c|c|c|c|c|}
\hline & Arsenite & Dimethylarsinate & Monomethylarsonate & Arsenate \\
\hline Sample 1 & $<\mathrm{LOD}$ & $53.18 \pm 4.04$ & $4.55 \pm 0.42$ & $4.45 \pm 0.38$ \\
\hline Sample 2 & $<\mathrm{LOD}$ & $51.07 \pm 2.01$ & $4.87 \pm 0.48$ & $0.38 \pm 0.21$ \\
\hline Sample 3 & $<\mathrm{LOD}$ & $17.32 \pm 1.10$ & $4.01 \pm 0.35$ & $3.24 \pm 0.14$ \\
\hline Sample 4 & $<\mathrm{LOD}$ & $33.92 \pm 1.49$ & $3.86 \pm 0.39$ & $4.46 \pm 0.39$ \\
\hline Sample 5 & $<\mathrm{LOD}$ & $71.14 \pm 3.97$ & $5.83 \pm 0.51$ & $4.48 \pm 0.34$ \\
\hline
\end{tabular}

$<$ LOD: below detection limit $(0.15 \mu \mathrm{g} / \mathrm{L})$.

lyze the lower concentration of urinary arsenic metabolites present in human samples. A previous study conducted in 2010 using a HPLC-ICP-MS method showed detection limits ranging from 0.092 to $0.197 \mu \mathrm{g} / \mathrm{L}$ [23], which is a similar range to our detection limits, hence, this method for separation of arsenic metabolites could be considered as being a reliable analysis method for assessment of arsenic exposure.

Among arsenic metabolites, DMA is the main metabolite in urinary excretion under normal conditions without excessive ingestion of inorganic arsenic. Excretion ratios are usually 10\%$20 \%$ for inorganic arsenic, 10\%-20\% for MMA, and 60-80\% DMA, respectively [24]. The present values for each arsenic species in our study using HPLC-ICP-MS show reasonable ratios in all arsenic metabolites and obtained results also show reliable ratios of each arsenic metabolite. The stability of retention time plays an important role in the reliable identification of each arsenic metabolite, because the identity of chromatographic peaks is normally obtained by comparing the retention time of the analysis of the sample with those of the standards. Therefore, we evaluated the retention time using a mixed calibration solution, then gathered recovery rates of each arsenic metabolite using certified materials. Using this method, calibration chro- 
matograms were obtained from HPLC-ICP-MS analyses. Only $40 \mu \mathrm{L}$ of sample had to be injected for the analysis, and excellent linearity measurements were obtained with $r^{2}=0.999$. Further recovery rates using the G-EQUAS No. 52 certified material were in accordance with those obtained by others, whose recoveries were in the range of 87 to $105 \%$ for $\mathrm{As}^{3+}, 82$ to $112 \%$ for DMA, 89 to $111 \%$ for MMA, and 91 to $107 \%$ for $\mathrm{As}^{5+}[25,26]$. Thus, we used this approach to check whether there was any interference with quantitative determination of arsenic species in urine samples. Analysis of five human urine samples using HPLC-ICP-MS revealed that inorganic arsenic species did not exceed the range reported by ACGIH. On the other hand, organic arsenic, especially DMA, showed higher results compared to other reports. Because, eating seafood was not strictly prohibited for 3 days before collecting these urine samples, it can be assumed that DMA concentrations might have been affected by seafood ingestion. It is well known that seafood ingestion can lead to misleading results, so seafood consumption is usually prohibited for at least 3 days before urine collection [18]. However, the current study introduces a method for separating arsenic metabolites in urine samples using HPLC-ICP-MS. We strongly suggest that continuous monitoring of the general population in Korea for arsenic metabolites in urine samples using HPLC-ICP-MS will provide significant information for the arsenic exposure index and contribute to the evaluation of health effect assessments from arsenic exposure in South Korea.

\section{Acknowledgements}

This research was conducted by the Heavy Metal Exposure Environmental Health Center at Dong-A University supported by the Ministry of Environment.

\section{Conflicts of Interest}

The authors have no conflicts of interest with the material presented in this paper.

\section{References}

1. Gibb H, Haver C, Gaylor D, Ramasamy S, Lee JS, Lobdell D, et al. Utility of recent studies to assess the National Research Council 2001 estimates of cancer risk from ingested arsenic. Environ Health Perspect 2011;119(3):284-290.

2. Argos M, Kalra T, Rathouz PJ, Chen Y, Pierce B, Parvez F, et al. Arsenic exposure from drinking water, and all-cause and chronic-disease mortalities in Bangladesh (HEALS): a prospective cohort study. Lancet 2010;376(9737):252-258.

3. International Agency for Research on Cancer. Arsenic and arsenic compounds [cited 2014 Aug 14]. Available from: http://monographs.iarc.fr/ENG/Monographs/vol100C/mono100C-6.pdf.

4. Ferreccio C, González C, Milosavjlevic V, Marshall G, Sancha AM, Smith AH. Lung cancer and arsenic concentrations in drinking water in Chile. Epidemiology 2000;11(6):673-679.

5. Rossman TG, Uddin AN, Burns FJ. Evidence that arsenite acts as a cocarcinogen in skin cancer. Toxicol Appl Pharmacol 2004; 198(3):394-404.

6. Milton AH, Smith W, Rahman B, Hasan Z, Kulsum U, Dear K, et al. Chronic arsenic exposure and adverse pregnancy outcomes in Bangladesh. Epidemiology 2005;16(1):82-86.

7. Lee MY, Bae ON, Chung SM, Kang KT, Lee JY, Chung JH. Enhancement of platelet aggregation and thrombus formation by arsenic in drinking water: a contributing factor to cardiovascular disease. Toxicol Appl Pharmacol 2002;179(2):83-88.

8. Bodwell JE, Kingsley LA, Hamilton JW. Arsenic at very low concentrations alters glucocorticoid receptor (GR)-mediated gene activation but not GR-mediated gene repression: complex dose-response effects are closely correlated with levels of activated GR and require a functional GR DNA binding domain. Chem Res Toxicol 2004;17(8):1064-1076.

9. Tseng CH, Tai TY, Chong CK, Tseng CP, Lai MS, Lin BJ, et al. Long-term arsenic exposure and incidence of non-insulin-dependent diabetes mellitus: a cohort study in arseniasis-hyperendemic villages in Taiwan. Environ Health Perspect 2000;108(9):847-851.

10. Drobná Z, Walton FS, Paul DS, Xing W, Thomas DJ, Stýblo M. Metabolism of arsenic in human liver: the role of membrane transporters. Arch Toxicol 2010;84(1):3-16.

11. Hakala E, Pyy L. Assessment of exposure to inorganic arsenic by determining the arsenic species excreted in urine. Toxicol Lett 1995;77(1-3):249-258.

12. Ma M, Le XC. Effect of arsenosugar ingestion on urinary arsenic speciation. Clin Chem 1998;44(3):539-550.

13. Lee SK, Yoo YC, Kwon TJ, Ko YC, Yang JY, Lee SY, et al. Distribution of arsenic in Korean human tissue. Cheongju: National Toxicological Program; 2002, p. 467-478 (Korean).

14. Byun K, Won YL, Hwang YI, Koh DH, Im H, Kim EA. Assessment of arsenic exposure by measurement of urinary speciated inorganic arsenic metabolites in workers in a semiconductor manufacturing plant. Ann Occup Environ Med 2013;25(1):21.

15. Hindmarsh JT, McCurdy RF. Clinical and environmental aspects of arsenic toxicity. Crit Rev Clin Lab Sci 1986;23(4):315-347.

16. Valentine JL, Kang HK, Spivey G. Arsenic levels in human blood, urine, and hair in response to exposure via drinking water. Environ Res 1979;20(1):24-32.

17. Buchet JP, Lauwerys R, Roels H. Urinary excretion of inorganic arsenic and its metabolites after repeated ingestion of sodium metaarsenite by volunteers. Int Arch Occup Environ Health 1981;48(2): 111-118.

18. Le XC, Cullen WR, Reimer KJ. Human urinary arsenic excretion after one-time ingestion of seaweed, crab, and shrimp. Clin Chem 1994;40(4):617-624.

19. Mandal BK, Suzuki KT. Arsenic round the world: a review. Talanta 2002;58(1):201-235.

20. Komorowicz I, Barałkiewicz D. Arsenic and its speciation in water samples by high performance liquid chromatography inductively 
coupled plasma mass spectrometry--last decade review. Talanta 2011;84(2):247-261.

21. Lai MS, Hsueh YM, Chen CJ, Shyu MP, Chen SY, Kuo TL, et al. Ingested inorganic arsenic and prevalence of diabetes mellitus. Am J Epidemiol 1994;139(5):484-492.

22. Tsai SM, Wang TN, Ko YC. Mortality for certain diseases in areas with high levels of arsenic in drinking water. Arch Environ Health 1999;54(3):186-193.

23. Chen LW, Lu X, Le XC. Complementary chromatography separation combined with hydride generation-inductively coupled plasma mass spectrometry for arsenic speciation in human urine. Anal Chim Acta 2010;675(1):71-75.
24. Buchet JP, Lauwerys R, Roels H. Comparison of the urinary excretion of arsenic metabolites after a single oral dose of sodium arsenite, monomethylarsonate, or dimethylarsinate in man. Int Arch Occup Environ Health 1981;48(1):71-79.

25. Coelho NM, Coelho LM, Lima ES, Pastor A, Guardia Mde L. Determination of arsenic compounds in beverages by high-performance liquid chromatography-inductively coupled plasma mass spectrometry. Talanta 2005;66(4):818-822.

26. Roig-Navarro AF, Martinez-Bravo Y, López FJ, Hernández F. Simultaneous determination of arsenic species and chromium (VI) by high-performance liquid chromatography-inductively coupled plasma-mass spectrometry. J Chromatogr A 2001;912(2):319-327. 

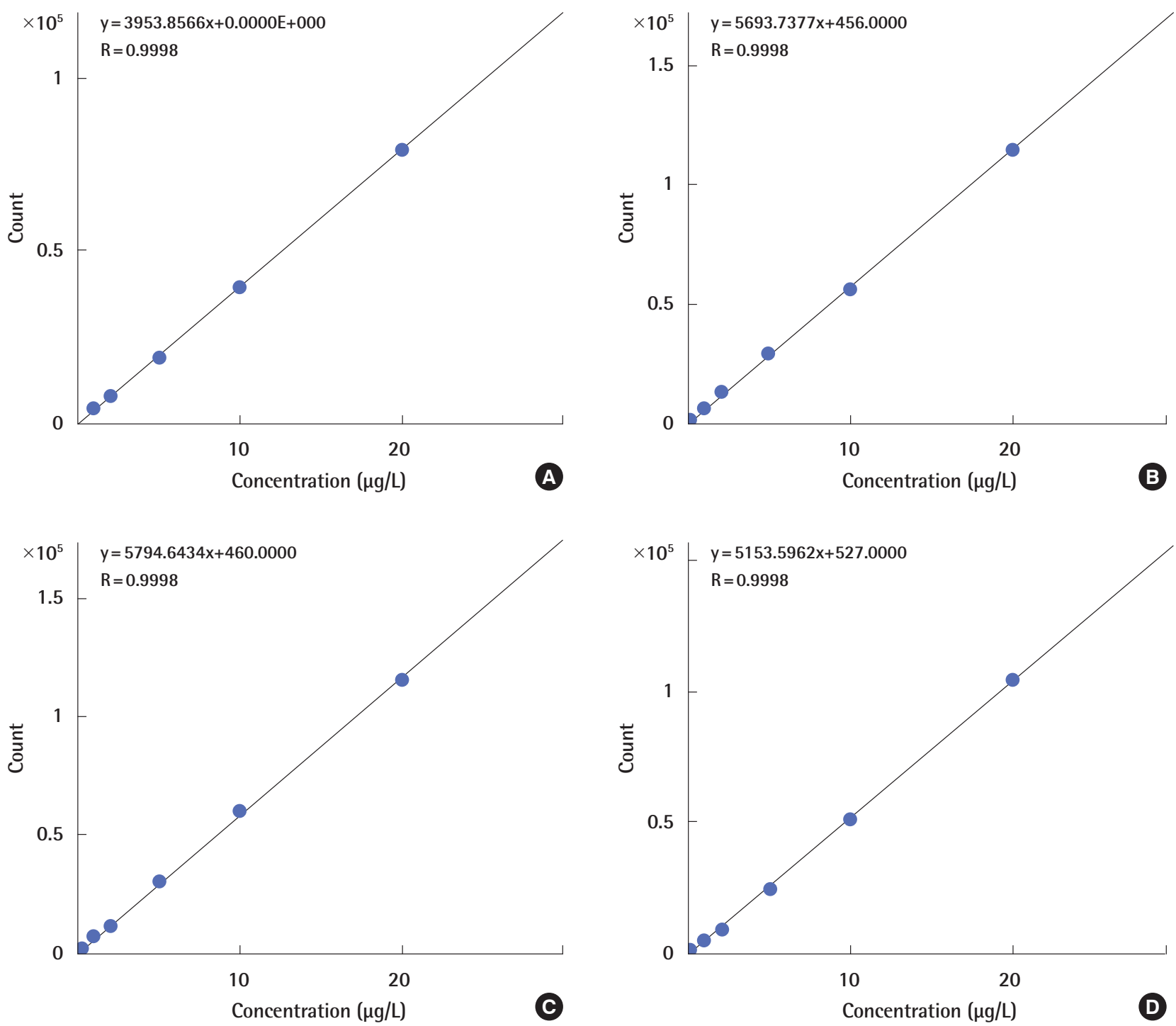

Figure S1. Calibration curves obtained from each arsenic metabolite (A) arsenite, (B) arsenate, $(C)$ monomethylarsonate, and (D) dimethylarsinate, ranging from 1 to $20 \mu \mathrm{g} / \mathrm{L}$ using HPLC-ICP-MS. $A s^{3+}$, arsenite; $\mathrm{As}^{5+}$, arsenate; DMA, dimethylarsinate; MMA, monomethylarsonate. 


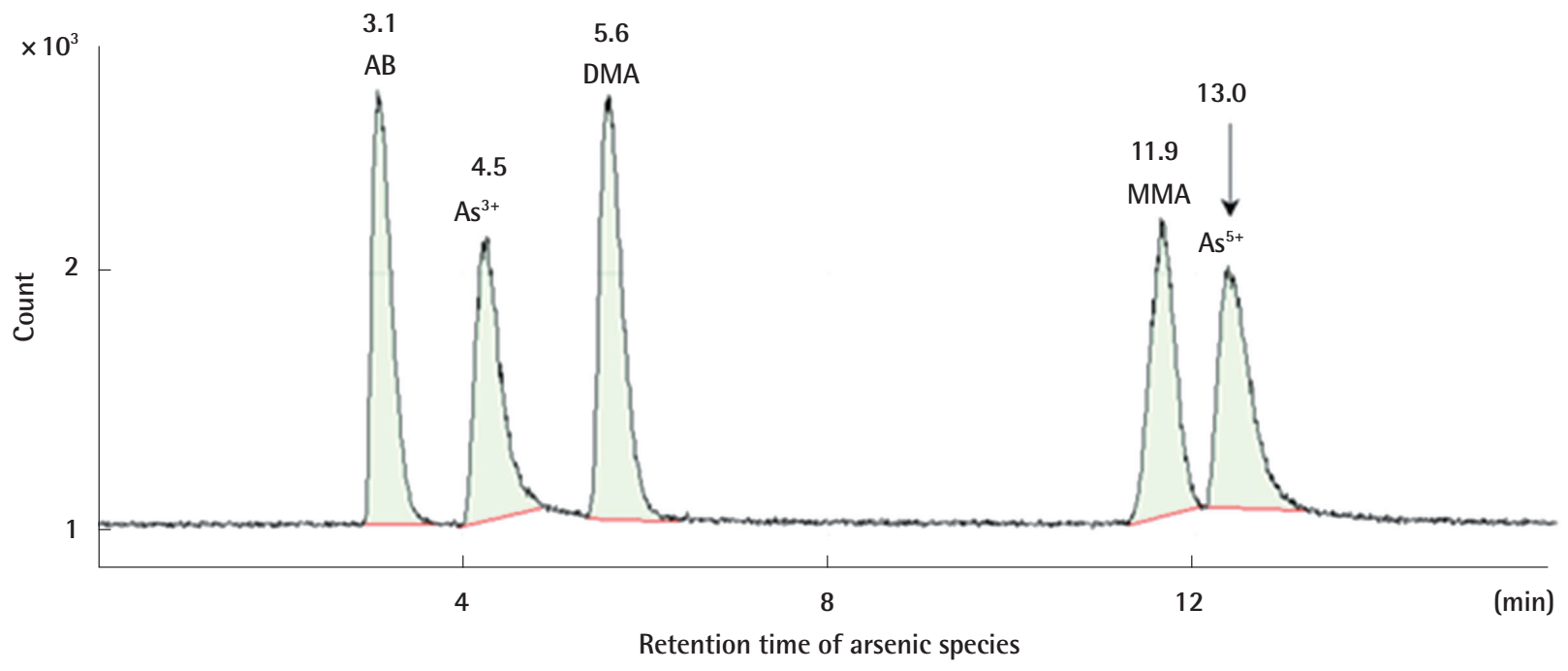

Figure S2. Chromatogram for arsenic metabolites obtained from HPLC-ICP-MS analysis. AB, arsenobetaine; $\mathrm{As}^{3+}$, arsenite; DMA, dimethylarsinate; MMA. monomethylarsonate; $\mathrm{As}^{5+}$, arsenate. 